\title{
Prebióticos na nutrição de não ruminantes
}

\author{
Prebiotics in nonruminants nutrition
}

\author{
Leila Picolli da Silva ${ }^{1}$ José Laerte Nörnberg ${ }^{2}$
}

\section{- REVISÃO BIBLIOGRÁFICA -}

\section{RESUMO}

A crescente restrição ao uso de drogas veterinárias como promotores de crescimento na nutrição animal fez com que surgisse uma nova geração de produtos para auxiliar no equilibrio benéfico da microbiota do trato gastrintestinal (TGI), entre eles, os prebióticos. Prebióticos são compostos não digeridos por enzimas, sais e ácidos produzidos pelo organismo animal, mas seletivamente fermentados por microrganismos do TGI. Estes compostos podem atuar beneficamente sobre a modulação da microbiota nativa, sobre o sistema imune e sobre a mucosa intestinal, melhorando os processos de digestão e absorção dos nutrientes. Porém, a adição de compostos de potencial ação prebiótica às dietas nem sempre reflete-se da mesma forma sobre a resposta biológica, o que pode estar relacionado com a composição dos ingredientes presentes na dieta, com a dosagem adicionada, com a adaptação e a seletividade da microbiota ao prebiótico, ou com o nível de estresse do animal.

Palavras-chave: microbiota intestinal, trato gastrintestinal, promotores de crescimento, oligossacarídios não digestiveis.

\section{ABSTRACT}

Due to the increasing constraint on the use of veterinary drugs as growth promoters in nonruminants nutrition there is a need to develop alternatives in supporting the microflora of the digestive tract in their approach to control pathogenic bacteria. The prebiotics are resistant compounds to digestion in the animal digestive tract, but selectively fermentable by intestinal microflora. These compounds can beneficially affect native microbiota, immune system and intestinal mucosal improving the digestion and absorption of nutrients. However, not always the use of the prebiotics causes alterations in the biological response. There may be several factors involved that partly explain the lack of response, such as: differences in the chemical composition of the ingredients of the diet, differences in the levels (percentage) of the prebiotics used in the diet, adaptation and the selectivity of the microflora and stress factors.

Key words: intestinal microflora, gastrointestinal tract, growth promoting, non-digestible oligosaccharides.

\section{INTRODUÇÃO}

Os prebióticos são compostos não digeridos por enzimas, sais e ácidos produzidos pelo organismo animal, mas seletivamente fermentados pelos microrganismos do trato gastrintestinal (TGI) que podem estar presentes nos ingredientes da dieta ou adicionados a ela através de fontes exógenas concentradas (GIBSON \& ROBERFROID, 1995; ROY \& GIBSON, 1999). Atualmente, estes compostos vêm sendo utilizados como alternativa aos promotores de crescimento com o objetivo de manter o equilíbrio benéfico da microbiota intestinal, especialmente em animais jovens ou em iminente condição de estresse.

Logo após o nascimento, as superfícies e mucosas dos animais, que, em condições fetais, são estéreis, rapidamente sofrem colonização por diversos microrganismos. Destes, alguns são úteis e outros nocivos. A microbiota útil auxilia na digestão e absorção de nutrientes, produz vitaminas que serão utilizadas pelo hospedeiro e diminui, por exclusão competitiva, a proliferação de agentes patogênicos (ROY \& GIBSON, 1999). A nociva pode causar inflamações na mucosa intestinal, gerar metabólitos tóxicos e propiciar o aparecimento de enfermidades. Em condições normais, estas populações encontramse em equilíbrio. No entanto, em condições de estresse

${ }^{1}$ Engenheiro Agrônomo, Doutor, Bolsista ProDoc, Beneficiária de auxílio financeiro CAPES Núcleo Integrado de Desenvolvimento de Análises Laboratoriais (NIDAL), Departamento de Tecnologia e Ciência dos Alimentos (DCTA), Centro de Ciências Rurais (CCR), Universidade Federal de Santa Maria (UFSM), Camobi, 97105-900, Santa Maria-RS. E-mail: leilasliva@bol.com.br Autor para correspondência.

${ }^{2}$ Médico Veterinário, Professor, Doutor, DCTA, CCR, UFSM. 
(mudança da dieta, alterações climáticas, densidade elevada, ventilação deficiente ou qualquer outra situação desfavorável) as populações úteis diminuem e as nocivas se proliferam, o que se reflete negativamente sobre a saúde e o desempenho animal (MATHEW et al., 1993).

Para manter o equilíbrio benéfico da microbiota do TGI mesmo em condições de estresse, os principais produtos usados nas últimas cinco décadas foram os antibióticos e os quimioterápicos que, em doses subterapêuticas, atuam como promotores de crescimento, diminuindo os índices de mortalidade e aumentando a eficiência produtiva e reprodutiva (SALYERS, 1999). No entanto, a restrição destes produtos na nutrição animal tem se tornado crescente nos últimos anos, uma vez que ao seu uso é atribuído o aumento da resistência de bactérias patogênicas aos tratamentos com antibióticos na saúde humana e animal (SPRING, 1999).

Ainda que este assunto mereça ser melhor explorado, produtos alternativos, capazes de manter o equilíbrio da microbiota sem causar prejuízos à saúde, tais como os prebióticos, vêm sendo pesquisados e desenvolvidos (McINTOSH, 1996). Isso se baseia em novos conceitos de segurança alimentar e evidencia a necessidade de um melhor entendimento sobre a natureza, modo de ação e reflexos do uso destes compostos sobre o desempenho animal.

\section{HISTÓRICO}

No último século, vários estudos na nutrição humana e animal têm relacionado a diminuição de ocorrência de doenças, o bom funcionamento do organismo e o aumento na expectativa de vida com a modulação do ecossistema intestinal (SALMINEN, 1996). De fato, alguns grupos de bactérias são capazes de inibir a proliferação de microrganismos patogênicos, estimular o sistema imune e evitar ou abrandar a síntese de compostos tóxicos e mutagênicos (KLEEMAN \& KLAENHAMMER, 1982; LÓPEZ, 2000). No entanto, a manutenção destas populações está intimamente relacionada com o tipo de alimento consumido pelo indivíduo.

Embora o termo "prebiótico" tenha sido adotado somente em 1995 (GIBSON \& ROBERFROID, 1995) os estudos sobre eles são bem mais antigos. Na década de 50, a descoberta de que o leite humano possui compostos que atuam como inibidores de adesão de bactérias patogênicas na superfície epitelial (posteriormente identificado como lactulose) e potencializam o crescimento das populações de bifidobactérias e lactobacillus, aliviando os sintomas de encefalopatia hepática em bebês (ROY \& GIBSON, 1999; WALKER \& DUFFY, 1998; NICOLI \& VIEIRA, 2000) incentivou outras explorações sobre o efeito do consumo de compostos não digestíveis na microbiota intestinal (FARNWORTH et al., 1992; MATHEW et al., 1993; SUNVOLD et al., 1995; MITSUOKA, 1996; HOUDIJK et al., 1998; KULLEN et al., 1998; SHEEHY \& MORRISSEY, 1998; STRICKLING et al., 2000).

A partir destes estudos, foi constatado que, apesar de existirem vários compostos resistentes à digestão por ácidos, sais e enzimas produzidos pelo organismo animal, mas potencialmente fermentáveis (celulose, hemiceluloses, amido resistente, oligossacarídios, compostos fenólicos, etc), nem todos agiam como estimuladores no desenvolvimento dos microrganismos benéficos no TGI. Ou seja, o fato de serem indigestíveis mas fermentáveis, não significava que iriam atuar como prebióticos (MACFARLANE \& CUMMINGS, 1999). Neste contexto, os oligossacarídios não digestíveis (ONDs) têm sido preferencialmente usados como prebióticos devido a sua maior seletividade fermentativa (MOSENTHIN \& BAUER, 2000).

A maioria dos ONDs estudados atualmente são produtos comerciais obtidos por hidrólise parcial, ácida ou enzimática, de polissacarídios ou por reações de transglicosilação (LEWIS, 1984). Porém, eles também podem ser obtidos diretamente de sua fonte natural (vegetais, leite, parede celular de leveduras) (ROBERFROID et al., 1993; OKU, 1996; MAXWELL, 1999; MACFARLANE \& CUMMINGS, 1999). Neste caso, os alimentos usados na formulação das dietas devem fornecer níveis de ONDs suficientes para garantir a sua atuação como agentes prebióticos.

\section{FORMAS DE AÇÃO E RESPOSTA AO USO DOS PREBIÓTICOS}

A principal forma de ação dos prebióticos é sobre a modulação benéfica da microbiota nativa presente no hospedeiro. Especula-se, também, que alguns prebióticos específicos poderiam agir diretamente sobre a translocação intestinal de patógenos, impedindo a sua aderência às células epiteliais e ativando a resposta imune adquirida (MATHEW et al., 1993, COLETT, 2000; MACARI \& MAIORKA, 2000; SILVA, 2000). Os efeitos resultantes do uso de prebióticos são evidenciados pelo crescimento das populações microbianas benéficas, pela melhora nas condições luminais, nas características anatômicas do TGI e no sistema imune e, em alguns casos, pela melhora no desempenho animal. 


\section{MODULAÇÃO DA MICROBIOTA INTESTINAL}

A colonização e a diversidade das populações de microrganismos presentes no TGI são influenciadas por inúmeros fatores, dentre os quais, pela disponibilidade de nutrientes, pelo $\mathrm{pH}$ luminal, pela presença de substâncias antibacterianas e pelo estímulo do sistema imune (RADECKI \& YOKOYAMA, 1991; SILVA, 2000).

Quando os prebióticos são adicionados à dieta, a especificidade de sua fermentação estimula o crescimento e a estabilidade das populações microbianas produtoras de ácidos orgânicos (em especial, ácido láctico e acético), em detrimento às demais. Estes compostos reduzem o $\mathrm{pH}$ luminal e, juntamente com outras substâncias antibacterianas e enzimas produzidas por esta mesma microbiota, inibem a proliferação dos microrganismos nocivos, tais como Escherichia coli, Clostridium sp. e Salmonella, que são sensíveis a ambientes ácidos (RADECKI \& YOKOYAMA, 1991).

Existe também a possibilidade de que determinados oligossacarídios, como a staquiose, as galactanas e as mananas, atuem diretamente sobre algumas populações de bactérias patogênicas, por meio de exclusão competitiva. Este mecanismo é explicado da seguinte forma: para que certas populações de bactérias nocivas colonizem o trato precisam, inicialmente, aderir às células epiteliais. Esta fixação ocorre através das fímbrias ou glicocalix. Em muitos casos, o elo entre os glicocálixes é a lectina, que se liga especificamente a um único carboidrato (MATHEW et al., 1993; COLLETT, 2000; MACARI \& MAIORKA, 2000). Existem evidências de que os oligossacarídios anteriormente citados atuariam exatamente nesta fase de colonização, se ligando às fímbrias e tornando-as indisponíveis para a aderência de bactérias patogênicas, as quais perderão a sua capacidade de colonização e serão eliminadas do TGI (COLETT, 2000).

Os resultados experimentais obtidos por MATHEW et al. (1993), que adicionaram 1\% de galactanas, e por GEBBINK et al. (2000) (Figura 1), que adicionaram 5\% de fruto-oligossacarídio (FOS) em dietas para leitões recém desmamados, demonstram a ação efetiva destes compostos no aumento na população de bactérias lácticas, redução do $\mathrm{pH}$ e diminuição na contagem de Escherichia coli. Da mesma forma, STANLEY et al. (1996a) observaram significativa redução na contagem de coliformes totais $\left(2 \log _{10}\right)$ em cecos de frangos de corte que receberam $0,2 \%$ de lactulose na dieta. Em experimento conduzido com cães, STRICKLING et al. (2000) também observaram diminuição na população fecal de Clostridium perfringens nos animais suplementados com um produto comercial a base de mananoligossacarídios.

Em humanos, OKU (1996) constatou que a ingestão de $0,18 \mathrm{~g} / \mathrm{kg}$ peso corporal/dia de galactosilsacarose aumentou significativamente a população de Bifidobacterium sp., diminuiu a percentagem de Eubasterium sp. e reduziu a concentração de produtos putrefativos e a atividade da $\beta$-glicuronidase. Adicionalmente, MACFARLANE \& CUMMINGS (1999) observaram que a ingestão de 8 a $15 \mathrm{~g} /$ dia de frutooligossacarídios aumentou em 10 vezes a população de bifidobactérias nas fezes, ao mesmo tempo que reduziu a contagem de clostridia e enterobactérias.

No entanto, os resultados obtidos por FARNWORTH et al. (1992) (Figura 1), GABERT et al. (1994) e ORBAN et al. (1997) em experimento com leitões, e os obtidos por FAIRCHILD et al. (1999) em experimentos com perus, demonstram que nem sempre a ingestão de compostos com potencial ação prebiótica causa mudanças na microflora e no pH do TGI. Este fato pode estar relacionado às diferenças de composição da microbiota entre as espécies animais, às diferenças na estrutura química e propriedades físico-químicas ou à variação na percentagem de compostos prebióticos presentes ou adicionados à dieta.

Os resultados obtidos por SUNVOLD et al. (1995), nos quais foram observadas variações significativas na produção individual de ácidos graxos voláteis (AGVs), quando um mesmo substrato (celulose, polpa de beterraba, polpa cítrica ou pectina cítrica) era submetido a fermentação com diferentes inóculos fecais (gato, cão, cavalo, humano e suíno), sugerem que as populações microbianas das diversas espécies animais diferem não só em composição, como também, apresentam peculiaridades quanto às rotas metabólicas para a fermentação de um mesmo substrato.

Quanto à influência da composição química e das propriedades físico-químicas dos prebióticos, SUNVOLD et al. (1995) constataram que diferentes substratos submetidos a um mesmo inóculo produziam quantidades significativamente variáveis de acetato, propionato, butirato e lactato. Da mesma forma, STRICKLING et al. (2000) observaram diferenças na produção de AGVs na digesta ileal de cães, quando adicionados diferentes ONDs à dieta. KULLEN et al. (1998), ao estudarem o efeito de três ONDs sobre a população cecal de bifidobactérias e Clostridium perfringens em ratos, verificaram que dois deles 
(oligossacarídio de farelo de trigo - WBOS e oligossacarídio de soja - SBOS) provocaram aumento em ambas populações microbianas, enquanto o tratamento com frutooligossacarídios (FOS) não diferiu do controle. In vitro, utilizando um meio de cultura composto por WBOS associado à presença de bifidobactérias, ocorria redução significativa no desenvolvimento de Clostridium perfringens. Embora todos os ONDs testados tenham causado um aumento em ambas as populações bacterianas, WBOS e SBOS foram utilizados mais eficientemente pelas bifidobactérias do que por Clostridium perfringens. VAN LAERE et al. (1997) observaram que os oligossacarídios não digestíveis de cadeia linear são fermentados mais extensivamente e por um maior número de espécies bacterianas do que os de cadeia ramificada. Aliado a este fato, as bifidobactérias utilizam inicialmente os ONDs com um baixo grau de polimerização, ao passo que os bacterióides degradam preferencialmente os ONDs com alto grau de polimerização.

Realizando um compilamento de dados, observou-se que a adição de prebióticos às dietas varia de 0,1 a $5 \%$ o que, provavelmente, também influencia no tipo de resposta obtida. Eventuais sub-doses podem causar efeito limitado ou nulo sobre a microbiota. Já uma superdosagem pode provocar um desequilíbrio sobre as populações microbianas. MACFARLANE \& CUMMINGS (1999) relatam que doses elevadas de frutooligossacarídios causam efeito laxativo e excesso na produção de gases em humanos, o que caracteriza um desequilíbrio na microbiota do TGI.

Outras explicações para as distintas respostas obtidas na utilização de compostos de potencial ação prebiótica, podem estar relacionadas com as condições do lúmen e/ou das paredes intestinais do hospedeiro, bem como, com a presença de bactérias degradadoras dos compostos testados como prebióticos nos diferentes compartimentos do TGI (MOSENTHIN \& BAUER, 2000; VAN LAERE, 2000). HOUDIJK (1998), ao fornecer $40 \mathrm{~g} /$ dia de diferentes ONDs para leitões, constatou que mais de $90 \%$ do FOS foi degradado pré-cecalmente, enquanto para TOS (transgalactooligossacarídio) este valor foi de $30 \%$, o restante ficou disponível para as populações bacterianas do ceco e intestino grosso. Estes resultados demonstram que dependendo do tipo de composto e da variação na população microbiana presentes nos diferentes segmentos do TGI, a fermentação poderá ocorrer em locais específicos do trato, o que levanta a hipótese que o uso combinado de compostos pode potencializar e prolongar o efeito prebiótico no organismo animal.

\section{INFLUÊNCIA SOBRE O SISTEMA IMUNE E CARACTERÍSTICAS ANATÔMICAS DO TRATO GASTRINTESTINAL}

Ao estimularem o crescimento das bactérias produtoras de ácido láctico, os prebióticos estão atuando indiretamente e de forma benéfica sobre o sistema imune do hospedeiro, pois estas populações bacterianas produzem substâncias com propriedades imuno-estimulatórias (ex. lipopolissacarídios, peptidoglicanas e ácidos lipoteicóicos) que interagem com o sistema imune em vários níveis, incluindo a produção de citoquinas, a proliferação de células mononucleares, a fagocitose macrofágica e a indução na síntese de grandes quantidades de imunoglobulinas, em especial as IgA (YASUI \& OHWAKI, 1991; BRANDTZAEG, 1998; MACFARLANE \& CUMMINGS, 1999).

Por ação direta, especula-se que alguns prebióticos específicos podem causar redução na translocação intestinal de patógenos (SILVA, 2000). Estes compostos se ligariam a sítios receptores dos macrófagos através do reconhecimento de determinados açúcares, presentes nas glicoproteínas da superfície epitelial, desencadeando uma reação em cascata que resultaria na ativação dos macrófagos e liberação de citoquinas, ativando a resposta imune adquirida (COLLETT, 2000). Os resultados obtidos por SAVAGE et al. (1996), que constataram aumentos significativos nos níveis de IgG do plasma e IgA da bile ao adicionarem $0,11 \%$ de MOS na dieta de perus, sustentam esta hipótese.

Adicionalmente, MITSUOKA (1992), McINTOSH(1996), ROBERFROID (1996), OKU (1996), SHEEHY \& MORRISSEY (1998) e MACFARLANE \& CUMMINGS (1999) comentam que os prebióticos promovem diminuição na atividade de enzimas envolvidas na produção de metabólitos genotóxicos ( $\beta$-glicuronidase, hidroxilase ácido-glicólica) e diminuem a concentração de produtos putrefativos e tóxicos nas fezes ( $N$-nitrosaminas, $\rho$-cresol, 4-etilfenol, fenóis, amônia, etc).

Os prebióticos também podem causar modificações benéficas nas características anatômicas do TGI, promovendo o aumento na área de absorção da mucosa intestinal. HOWARD et al. (1993) observaram aumento na densidade celular (número de células/cripta) e no número de células marcadas com 5-bromo-2-deoxipridina (número/cripta) da mucosa cecal de leitões que receberam adição de FOS em suas dietas. Neste tratamento, também foram observados maior comprimento das criptas, maior zona de 
proliferação (células marcadas/densidade celular), maior número e comprimento de células marcadas das partes proximal e distal do cólon, quando comparado ao controle. SAVAGE et al. (1997), ao fornecerem diferentes níveis de MOS em dietas para perus, observaram significativo aumento no número de células globulares e largura do vilus, bem como diminuição na profundidade da cripta nas regiões médio-distal do duodeno e na região proximal do divertículo de Meckel's. MACARI \& MAIORKA (2000) também relataram um aumento significativo na altura do vilo nos três segmentos do intestino delgado, em frangos de corte com 7 dias de idade que receberam $0,2 \%$ de MOS na dieta.

\section{EFEITOS SOBRE O DESEMPENHO ANIMAL}

Uma vez que os prebióticos estimulam o crescimento e a atividade de bactérias benéficas, que atuam positivamente no sistema imune e promovem melhorias no ambiente e no epitélio intestinal, esperase que o uso destes compostos também se reflita de forma desejável no desempenho animal.

Em experimentos realizados com leitões recém desmamados, GEBBINK et al. (2000) observaram que o ganho de peso dos animais mantidos em creches limpas, recebendo dieta suplementada com FOS, foi $9 \%$ superior ao tratamento controle e, quando em creches sujas, os que receberam FOS tiveram uma eficiência alimentar 14\% superior aos tratamentos controle e com antibiótico (Figura 1). HOUDIJK et al. (1999) verificaram depressão temporária no consumo e no ganho diário de peso de leitões (peso inicial de $20 \mathrm{~kg}$ ) recebendo dois níveis de suplementação de FOS $(7,5$ e $15 \mathrm{~g} / \mathrm{kg}) \mathrm{e}$ TOS (10 e $20 \mathrm{~g} / \mathrm{kg})$. Porém, o desempenho médio de crescimento durante todo o período experimental (6 semanas) não foi afetado. De acordo com os autores, esta depressão pode ter ocorrido devido a mudanças na microbiota intestinal, o que resultou em uma resposta imune não específica e conseqüente redução do consumo de dieta.

COLLETT (2000) relata que o fornecimento de 0,5 a $3 \%$ de MOS melhorou a conversão alimentar de frangos de corte (1 a 10\%) em relação ao tratamento controle. MACARI \& MAIORKA (2000) também verificaram maior ganho de peso em frangos suplementados com $0,2 \%$ de MOS quando comparados aqueles que receberam o tratamento controle. Porém, estes resultados não se estenderam às respectivas conversões alimentares. STANLEY et al. (1996b) observaram maior conteúdo em músculo e menores níveis de colesterol e gordura no peito e fígado, respectivamente, quando fornecido $0,05 \%$ de MOS (Bio-MOS ${ }^{\circledR}$ ) em dietas para frangos de corte.

No entanto, os resultados positivos sobre o desempenho animal com adição de compostos de ação prebiótica às dietas nem sempre são evidenciados. FARNWORTH et al. (1992) (Figura 1) e ORBAN et al. (1997) observaram que a adição de farinha de alcachofra de Jerusalém, FOS ou sacarose caramelada não surtiram efeito sobre o desempenho de suínos. Esta ausência de efeitos pode estar relacionada com o tipo de ingredientes que compõem a dieta, com a adaptação da microbiota ao composto adicionado ou com o nível de estresse do animal.

A maior percentagem das dietas animais são compostas por ingredientes derivados de grãos de cereais (ex. milho, trigo, cevada, etc) e oleaginosas (ex. grãos de soja, farelo de soja, etc), os quais apresentam níveis variados de polissacarídios não amiláceos (PNAs) e ONDs na sua composição química. Considerando que ambos os grupos são formados por compostos indigestíveis mas potencialmente fermentáveis pela microbiota intestinal, supõe-se que a falta de resposta em relação à adição de um determinado prebiótico pode estar vinculada a um efeito "diluidor" dos PNAs e ONDs derivados dos próprios ingredientes. Muitas vezes, os níveis destes compostos nos grãos e nos seus subprodutos (trigo, milho, farelo de trigo, farelo de aveia, farelo de soja) são bem superiores aos adicionados na dieta como prebióticos $(0,05$ a $3 \%)$.

A adição de um composto "estranho" à microbiota intestinal também pode provocar efeitos indesejáveis por um determinado período de tempo (HOUDIJK et al., 1999). Assim como o excesso no consumo de um determinado composto de reconhecida ação prebiótica pode causar desequilíbrio nas populações microbianas prejudicando a saúde (MACFARLANE \& CUMMINGS, 1999) e o desempenho animal.

O nível de estresse do animal também pode influenciar sobre a resposta biológica obtida pela adição de prebióticos à dieta. Se os animais estão em condições não estressantes, supõe-se que a microbiota esteja em condição de equilíbrio, ou seja, com ou sem o fornecimento de prebióticos as respostas obtidas serão muito semelhantes. No entanto, quando em condição de estresse (ventilação deficiente, superpopulação, variações ambientais bruscas, troca de dieta, presença de patógenos), o efeito do benéfico do fornecimento de prebióticos sobre a resposta biológica é evidenciado (MATHEW et al., 1993; MOSENTHIN \& BAUER, 2000). 


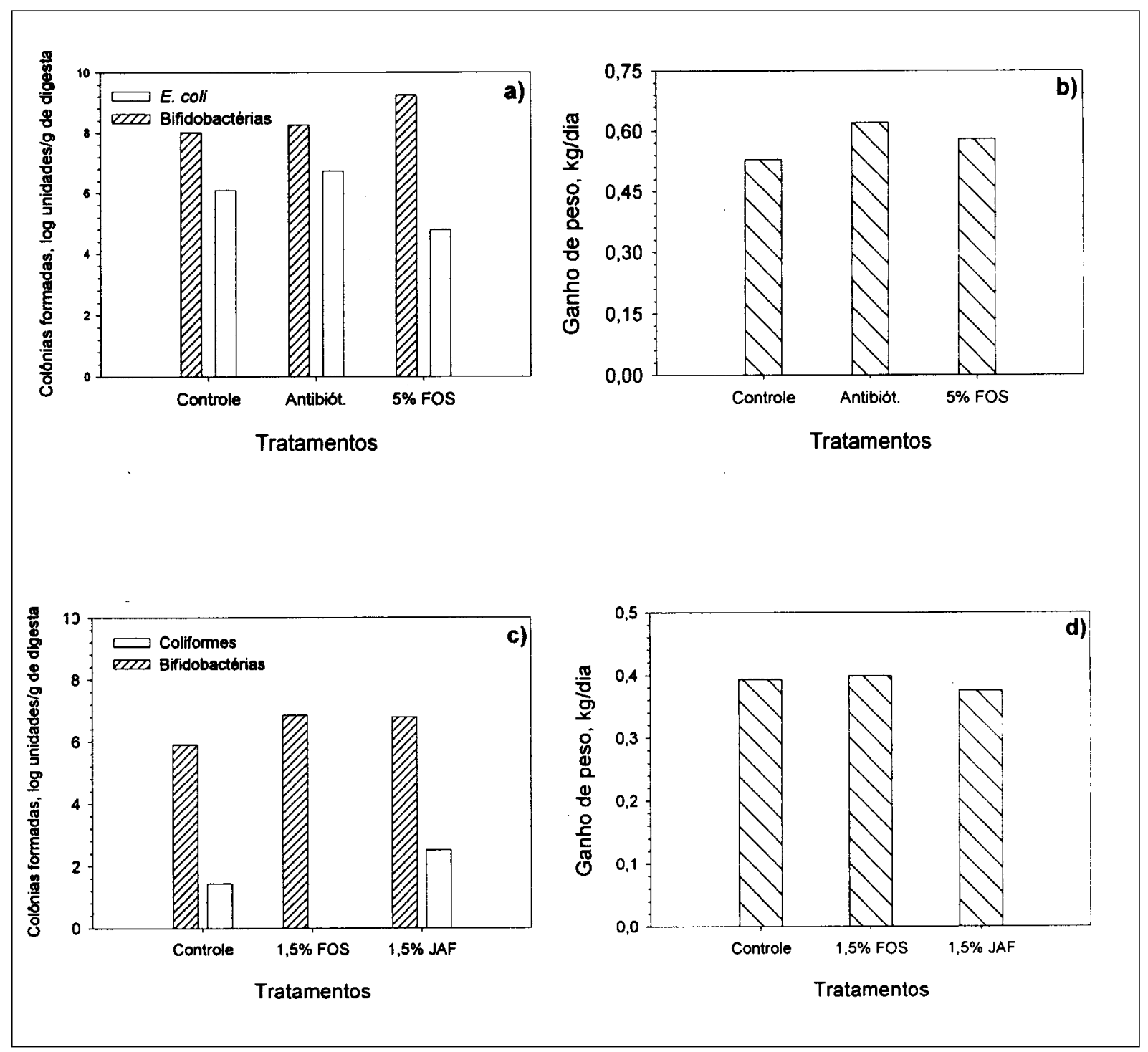

Outro fator a ser considerado é que os compostos mais usados atualmente como prebióticos não são tão seletivos, isto é, eles não são fermentados somente por bifidobactérias e/ou lactobacillus, mas também por populações potencialmente patogênicas (MITSUOKA, 1992; MOSENTHIN \& BAUER, 2000), o que diminui o seu efeito benéfico.

\section{CONCLUSÕES}

Os prebióticos são compostos biologicamente seguros à saúde humana e animal, justificando o seu uso alternativo em substituição a certas drogas veterinárias usadas na prevenção de alterações do trato gastrintestinal e/ou como promotoras do crescimento. Entretanto, as respostas biológicas na nutrição animal nem sempre são evidenciadas, o que pode estar relacionado com a composição química dos demais ingredientes da dieta, com a dosagem adicionada, com a adaptação e a seletividade da microbiota ao prebiótico, ou com o nível de estresse do animal. Assim, mais estudos se fazem necessários para esclarecer as condições nas quais há necessidade real de sua suplementação. 


\section{REFERÊNCIAS BIBLIOGRÁFICAS}

BERG, R.D. Probiotics, prebiotics or 'conbiotics'? Trends Microb, Oxford, v.6, n.3, p.89-92, 1998.

BRANDTZAEG, P. Development and basic mechanisms of human gut immunity. Nutr Rev, New York, v.56, n.1, supp. 2, p s5-s18, 1998.

COLLETT, S. Nutrição, imunidade e produtividade. In: RONDA LATINO-AMERICANA - O FUTURO DA ALIMENTAÇÃO, 10., 2000, Brasil. Palestras... Brasil : Alltech, 2000. p.20-30.

FAIRCHILD, A.S. et al. Effect of hen age, Bio-Mos and Flavomycin on suscetibility of turkey poults to oral Escherichia coli challenge In: ALLTECH'S ANNUAL SYMPOSIUM, 15., 1999, Nottingham. Proceedings... Nottingham : Alltech, 1999. p.185 - 201 .

FARNWORTH, E.R. et al. Feeding Jerusalem artichoke flour rich in fructooligosaccharides to weanling pigs. Can J Anim Sci, Ottawa, v.72, n.12, p.977-980, 1992.

GABERT, V.M. et al. The effect of oligosaccharides and lactitol on the ileal digestibilities of amino acids, monosaccharides and bacterial populations and metabolites in the small intestine of weanling pigs. Can J Anim Sci, Ottawa, v.75, n.1, p.99-107, 1994.

GEBBINK, G.A.R. et al. Effects of addition of frutooligosaccharide (FOS) and sugar beet pulp to weanling pig diets on performance, microflora and intestinal health. Capturado em 27 de junho de 2000. Online. Disponível na internet $\mathrm{http} / / \mathrm{www}$. ansc.purdue.edu/ swine/swineday/sday99/psd09-1999.html.

GIBSON, G.R.; ROBERFROID, B.M. Dietary modulation of the human colonic microbiota: introducing the concept of prebiotics. J Nutr, Bethesda, v.125, n.6, p.1401-1412, 1995.

HOSENEY, R.C. Principles of cereal science and technology. St. Paul : AACC, 1990. 327p.

HOUDIJK, J.G.M. Effects of non-digestible oligosaccharides in young pig diets. Wageningen University dissertation $\mathrm{n}^{\circ} 2550$, 1998. Capturado em 27 de junho de 2000. Online. Disponível na internet http:// www.bib.wau.ml/wda/abstracts/ab2801.html.

HOUDIJK, J.G.M.; BOSCH, M.W.; VERSTEGEN, M.W.A. Effects of dietary oligosaccharides on the growth performance and faecal characteristics of yong growing pigs. Anim Feed Sci Tech, Amsterdam, v.71, n.1, p.3548, 1998 .

HOUDIJK, J.G.M. et al. Apparent ileal and total-tract nutrient digestion by pigs as affected by dietary nondigestible oligosaccharides. J Anim Sci, Savoy, v.77, n.1, p.148-158, 1999.

HOWARD, M.D. et al. Effect of dietary addition of fructooligosaccharide on colonic microflora populations and epithelial cell proliferation in neonatal pigs. J Anim Sci, Savoy, v.71, supp.1, p.177, 1993
KLEEMAN, E.G.; KLAENHAMMER, T.R. Adherence of Lactobacillus species to human fetal intestinal cells. J Dairy Sci, Champaign, v.65, n.11, p.2063-2069, 1982.

KULLEN, M.J. et al. Carbohydrate source and bifidobacteria influence the growth of Clostridium perfringens in vivo and in vitro. Nutr Res, Oxford, v.18, n.11, p.1889-1897, 1998.

LEWIS, D.H. Storage carbohydrates in vascular plants: distribuition, physiology and metabolism. Cambrige : Cambrige University, 1984. 284p.

LÓPEZ, J. Probiotics in animal nutrition. In: INTERNATIONAL SYMPOSIUM ON RECENT ADVANCES IN ANIMAL NUTRITION, 2000, Seoul. Proceedings... Seoul : Seoul National University, 2000. p.33-54.

MACARI, M.; MAIORKA, A. Função gastrintestinal e seu impacto no rendimento avícola. In: CONFERÊNCIA APINCO'2000 DE CIÊNCIA E TECNOLOGIA AVÍCOLAS, 2000, Campinas. Anais... Campinas : FACTA, 2000. V.2. p.161-174

MACARTHUR, L.A.; D'APPOLONIA, L.D. Comparison of oat and wheat carbohydrates. I. Sugars. Cereal Chem, St. Paul, v.56, n.5, p.455-457, 1979.

MACFARLANE, G.T.; CUMMINGS, J.H. Probiotics and prebiotics: can regulating the activities of intestinal bacteria benefit health? BMJ, London, v.18, p.999-1003, 1999.

MATHEW, A.G. et al. Effect of galactan on selected microbial populations and $\mathrm{pH}$ and volatile fatty acids in the ileum of the weanling pig. J Anim Sci, Savoy, v.71, n.6, p.1503-1509, 1993.

MAXWELL, C. Nutrition and management of the earlyweaned pig In: ALLTECH'S ANNUAL SYMPOSIUM, 15., 1999, Nottingham. Proceedings... Nottingham : Alltech, 1999. p.203-222.

McINTOSH, G.H. Probiotics and colon cancer prevention. Asia Pacif J Clin Nutr, Oxfordshire, v.5, n.1, p.48-52, 1996.

MITSUOKA, T. Intestinal flora and aging. Nutr Rev, New York, v.50, n.12, p.438-446, 1992.

MITSUOKA, T. Intestinal flora and human health. Asia Pacif J Clin Nutr, Oxfordshire, v.5, n.1, p.2-9, 1996.

MOSENTHIN, R.; BAUER, E. The potential use of prebiotics in pig nutrition. In: INTERNATIONAL SYMPOSIUM ON RECENT ADVANCES IN ANIMAL NUTRITION, 2000, Seoul. Proceedings... Seoul : Seoul National University, 2000. p. 515-528.

ICOLI, J.R.; VIEIRA, L.Q. Probióticos, prebióticos e simbióticos - Moduladores do ecossistema digestivo. Ciência Hoje, São Paulo, v.28, n.163, p.34-38, 2000.

OKU, T. Oligosaccharides with beneficial health effects: A japanese perspective. Nutr Rev, New York, v.54, n.11, p.s59-s66, 1996.

ORBAN, J.I. et al. Growth performance and intestinal microbial populations of growing pigs fed diets containing thermal oligosaccharide caramel. J Anim Sci, Savoy, v.75, n.1, p.170$175,1997$.

Ciência Rural, v. 33, n. 5, set-out, 2003. 
RADECKI, S.V.; YOKOYAMA, M.T. Intestinal bacteria and their influence on swine nutrition. In: MILLER, E.R.; DUANE, E.U.; LEWIS, A.J. Swine nutrition. Boston : ButterworthHeinemann, 1991. p.439-447.

ROBERFROID, M.B.; GIBSON, G.R.; DELZENNE, N. The biochemistry of oligofructose, a nondigestible fiber: Approach to calculateits caloric value. Nutr Rev, New York, v.51, n.5, p.137-146, 1993.

ROBERFROID, M.B. Functional effects of food components and the gastrointestinal system: Chicory fructooligosaccharides. Nutr Rev, New York, v.54, n.11, supp.2, p.s38-s42, 1996.

ROY, M.; GIBSON, G.R. Probiotics and prebiotics microbal in menu. Capturado em 21 de novembro de 1999. Online. Disponível na internet http:// www.babelfish.altavista.com/cgi-bm.

SALYERS, A.A. Agricultural use of antibiotics and antibiotic resistance in human pathogens: is there a link? In: ALLTECH'S ANNUAL SYMPOSIUM, 15., 1999, Nottingham. Proceedings... Nottingham : Alltech, 1999. p.155-171.

SALMINEN, S. Functional dairy foods with Lactobacillus Strain GG. Nutr Rev, New York, v.54, n.11, supp.2, p.s99-s101, 1996.

SAVAGE, T.F.; COTTER, P.F.; ZAKRZEWSKA, E.I. The effects of feeding mannan oligosaccharide on Immunoglobulins, plasma IgG and bile IgA, of wrolstad MW male turkeys. Poultry Sci, Champaign, v.75, supp.1, p.143, 1996.

SAVAGE, T.F.; ZAKRZEWSKA, E.I.; ANDREASEN Jr., J.R. The effects of feeding diets to poults on performance and the morphology of the small intestine. Poultry Sci, Champaign, v.76, supp.1, p.139, 1997.

SHEEHY, P.J.A.; MORRISSEY, P.A. Functional foods: prospects and perspectives. In: HENRY, C.J.A.; HEPPELL, N.J. Nutritional aspects of food processing and ingredients. Gaithersburg : Aspen, 1998. p.45-65.

SILVA da, E.N. Probióticos e prebióticos na alimentação de aves. In: CONFERÊNCIA APINCO'2000 DE CIÊNCIA E TECNOLOGIA AVÍCOLAS, 2000, Campinas. Anais... Campinas : FACTA, 2000. V.2. p.241-251.
SPRING, P. The move away from antibiotic growth promoters in Europe. In: ALLTECH'S ANNUAL SYMPOSIUM, 15., 1999, Nottingham. Proceedings... Nottingham : Alltech, 1999. p.173-183.

STANLEY, V.G. et al. Effects of lactose and Bio-MOS in dietary application on growth and total coliform bacteria reduction in broiler chicks. Poultry Sci, Champaign, v.75, supp.1, p.61, 1996a.

STANLEY, V.G.; GRAY, C.; CHUKWU, H. Effects of mannan oligosaccharide (Bio-MOS) on liver and egg cholesterol and tissue protein concentration in chickens. Poultry Sci, Champaign, v.75, supp.1, p.61, 1996b.

SUNVOLD, G.D. et al. In vitro fermentation of celulose, beet pulp, citrus pulp, and citrus pectin using fecal inoculum from cats, dogs, horses, humans, and pigs and ruminal fluid from cattle. J Anim Sci, Savoy, v.73, p.3639-3648, 1995.

STRICKLING, J.A. et al. Evaluation of oligosaccharide addition to dog diets: influences on nutrient digestion and microbial populations. Anim Feed Sci Tech, Amsterdam, v.86, n.2, p.205-219, 2000.

VAN LAERE, K.M.J. Degradation of structurally different non-digestible oligosaccharides by intestinal bacteria: glycosylhydrolases of Bifidobacterium adolescentis. Wageningen University dissertation $\mathrm{n}^{\circ} 2801,2000$. Capturado em 27 de junho de 2000. Online. Disponível na internet http:/ /www.bib.wau.ml/wda/abstracts/ab2801.html.

VAN LAERE, K.M.J. et al. Fermentative degradation of plant cell wall derived oligosaccharides by intestinal bacteria. In: INTERNATIONAL SIMPOSYUM NON-DIGESTIBLE OLIGOSACCHARIDES: HEALTHY FOOD FOR THE COLON? 1997, Wageingen. Proceedings... Wageingen : Wageningen Institute of Animal Science, 1997. p.37-46.

WALKER, W.A.; DUFFY, L.C. Diet and bacterial colonization: Role of probiotics and prebiotics. J Nutr Biochem, New York, v.9, n.2, p.668-675, 1998.

YASUI, H.; OHWAKI, M. Enhancement of immune response in Peyer's patch cells cultured with Bifidobacterium breve. J Dairy Sci, Champaign, v.74, n.4, p.1187-1195, 1991 . 